\title{
Clinical Features of Fulminant Hepatitis in Nagasaki Prefecture, Japan
}

\author{
Yuji Kato, Keisuke NaKata, Katsuhisa Omagari*, Yukio Kusumoto**, Iwao Mori**, Ryuji Furukawa***, \\ Hajime TANIOKA $* * * *$, Heiichiro TAJIMA $* * * * *$, Michitami YANO $* * * * * *$ and Katsumi EGUCHI
}

\begin{abstract}
Objective Fulminant hepatitis is a rare but fatal disease. In the present study, we examined the changes in etiology and prognosis of fulminant hepatitis in Nagasaki Prefecture, Japan between 1980 to 1999.

Methods Eighty-one patients with fulminant hepatitis admitted to our hospitals from 1980 to 1999 were examined with respect to the etiology and prognosis.

Results Fulminant hepatitis was due to hepatitis A virus in $2(12 \%)$ cases, hepatitis B virus in $18(22 \%)$ cases, unknown etiology in $50(62 \%)$ cases, and drug-induced in $11(14 \%)$ cases. The number of cases in the first half of the study (1980-1989) was 47 and that of the latter half (19901999) was 34 cases. The incidence of fulminant hepatitis type $B$ also decreased from 14 cases $(30 \%)$ to 4 cases (12\%) during these periods. The overall survival rate of fulminant hepatitis was $32 \%$; it was equal in fulminant hepatitis type B, fulminant hepatitis of unknown etiology and fulminant drug-induced hepatitis. The survival rate of fulminant hepatitis type A was $100 \%$, though only two cases were identified. Retrospectively, the survival rate in patients with a pre-encephalopathy period of $\leq 10$ days and aged $\leq 39$ years was significantly higher than in patients $\geq \mathbf{4 0}$ years of age $(p<0.01)$. There was no difference between the two age groups when pre-encephalopathy period was $\geq \mathbf{1 1}$ days.

Conclusions The incidence of fulminant hepatitis especially that of fulminant hepatitis type $B$ in Nagasaki Prefecture has decreased in recent years. The survival rate is significantly higher in younger patients with a short preencephalopathy period.
\end{abstract}

(Intenal Medicine 40: 5-8, 2001)

Key words: etiology, survival rate

\section{Introduction}

Fulminant hepatitis is characterized by a rapidly fatal clinical course due to massive necrosis of the liver and encephalopathy. Even though viral hepatitis and drug-induced liver injury account for most cases of this rare form of hepatitis (1), we often experience difficulties in etiological diagnosis of fulminant hepatitis because of the rapid course. Recent studies have described new hepatitis viruses, such as GB virus C/hepatitis $\mathrm{G}$ virus (GBV-C/HGV) $(2,3)$ and TT virus (TTV) (4) but these viruses have not been reported to cause fulminant hepatitis $(5,6)$.

Nagasaki Prefecture is endemic for hepatitis B virus (HBV) infection (7). The mortality rate due to liver disease in this area is high compared to other areas of Japan (8). Recent studies have shown a decrease in the HBV carrier rate in Nagasaki Prefecture as well as in Japan and that the major form of liver diseases is from hepatitis $C$ virus (HCV) infection $(7,9,10)$. Though HBV infection is the major cause of fulminant hepatitis in Japan (11), the etiology and prognosis of fulminant hepatitis in this area have not been reported previously.

Various clinical trials on the treatment of fulminant hepatitis, such as plasma exchange or glucagon-insulin therapy, have been conducted because of its fatal course, but a marked improvement of prognosis has not been observed until now. Recently, a few centers in Japan have begun using liver transplantation. It is hoped that this treatment results in the improvement of prognosis in patients with fulminant hepatitis. In the present study, we investigated the changes in etiology and survival rates in patients with fulminant hepatitis admitted to our hospitals in the past 20 years.

\section{Methods}

Eighty-one patients with fulminant hepatitis were admitted

From the First Department of Internal Medicine, Nagasaki University School of Medicine, Nagasaki, *the Second Department of Internal Medicine, Nagasaki University School of Medicine, Nagasaki, **the Department of Internal Medicine, Nagasaki Municipal Hospital, Nagasaki, ***the Department of Internal Medicine, Nagasaki Red Cross Atomic Bomb Hospital, Nagasaki, ****the Department of Internal Medicine, Sasebo Municipal General Hospital, Sasebo, *****the Department of Internal Medicine, Nagasaki Rousai Hospital, Sasebo and ******the Institute for Clinical Research, Nagasaki Chuo National Hospital, Omura

Received for publication September 1, 1999; Accepted for publication July 31, 2000

Reprint requests should be addressed to Dr. Yuji Kato, the First Department of Internal Medicine, Nagasaki University School of Medicine, 1-7-1 Sakamoto, Nagasaki 852-8501 
to our regional hospitals between July 1980 and June 1999 . There was no history of blood transfusion or liver diseases in these patients. Clinical features and results of pertinent laboratory tests are summarized in Table 1. The criteria used for the diagnosis of fulminant hepatitis were based on those described by Trey et al (12) and included: i) development of stage II to IV hepatic encephalopathy within 8 weeks of the onset of illness; ii) prothrombin time $<40 \%$; and iii) no past history of liver disease.

The diagnosis of fulminant hepatitis type A was based on the presence of IgM anti-hepatitis A virus antibody (IgM anti$\mathrm{HAV}$ ). Diagnosis of fulminant hepatitis type B was established by the presence of $\operatorname{IgM}$ anti-hepatitis $B$ virus core antibody (IgM anti-HBc) or hepatitis B surface antigen (HBsAg). Fulminant hepatitis unknown etiology was established when IgM anti-HAV, IgM anti-HBc and $\mathrm{HBsAg}$ were negative and no obvious cause of drug was noted. Diagnosis of drug-induced fulminant hepatitis was established when an obvious cause of drug was identified. IgM anti-HAV was assayed in 72 patients and antibody to HCV (anti-HCV) was assayed by second or third generation radioimmunoassay in 30 patients. Tests for these virus markers were performed in all patients at the time of admission.

Fifty-one percent of patients were treated with plasma ex-

Table 1. Clinical Background of Patients with Fulminant Hepatitis

\begin{tabular}{ll}
\hline $\mathrm{n}$ & 81 \\
M/F & $30 / 51$ \\
Age (years) (range) & $47(12-90)$ \\
Survival rate (\%) & 32 \\
AST (IU/l) (range) & $1,320(42-7,500)$ \\
ALT (IU/l) (range) & $1,328(26-8,200)$ \\
TB (mg/dl) (range) & $17.4(0.5-41.5)$ \\
PT (\%) (range) & $22.8(0-39)$ \\
\hline
\end{tabular}

n: number, $M / F$ : males/females, IU/l: international unit/liter, AST: aspartate aminotransferase, ALT: alanine aminotransferase, TB: total bilirubin, PT: prothrombin time. change and 54\% received glucagon-insulin therapy. Fifty-one percent of patients were treated by corticosteroids and only one case was treated by liver transplantation. Statistical analysis was performed using the Student t-test and chi-square test. Differences between groups were considered statistically significant when $\mathrm{p}<0.05$.

\section{Results}

\section{Clinical background and etiology of fulminant hepatitis}

Of 81 patients, $2(2 \%)$ patients were classified as fulminant hepatitis type A, 18 (22\%) patients as fulminant hepatitis type B, 50 (62\%) patients as fulminant hepatitis of unknown etiology and 11 (14\%) patients as fulminant drug-induced hepatitis. The cause of fulminant drug-induced hepatitis was antituberculous drugs in 4 cases, halothane in 2 cases, 5 -fluorouracil in 2 cases, amoxicillin in 1 case, acetaminophen in 1 case and mercazole in 1 case. Anti-HCV was positive for 1 case though the relationship between fulminant hepatitis and HCV infection is not known. The sex ratio and pre-encephalopathy period were not different between the four groups. The mean age of patients with fulminant drug-induced hepatitis was significantly higher than those with fulminant hepatitis type B $(\mathrm{p}<0.001)$ and fulminant hepatitis of unknown etiology $(\mathrm{p}<0.05)$ (Table 2).

To examine changes in the etiology of fulminant hepatitis across the period of the study, we divided our patients into those diagnosed between 1980 to 1989 and the second group diagnosed between 1990 and 1999 (Table 3). The numbers of fulminant hepatitis in the second period ( 34 cases) was less than in the first period (47 cases). The sex ratio, mean age, preencephalopathy period and survival rate were similar between these two groups (Table 3). Figure 1 shows the sequential percent changes in the etiology of fulminant hepatitis. The frequency of fulminant hepatitis type B in the second period (4 cases, $12 \%$ ) was less than in the first period (14 cases, $30 \%$ ). The frequency of patients with fulminant hepatitis of unknown etiology in the second period ( 22 case, $65 \%$ ) was also lower than in the first period ( 28 cases, $60 \%$ ), though these percents were similar between these periods. In contrast, the frequency of fulminant drug-induced hepatitis was equal between these periods.

Table 2. Etiology of Fulminant Hepatitis

\begin{tabular}{lccccc}
\hline Etiology & $\mathrm{n}$ & $\mathrm{M} / \mathrm{F}$ & Age* & $\begin{array}{c}\text { Pre-encephalopathy } \\
\text { period (days) }\end{array}$ & $\begin{array}{c}\text { Survival rate } \\
(\%)\end{array}$ \\
\hline HAV & 2 & $2 / 0$ & 44 & $9.5(6-13)$ & 100 \\
HBV & 18 & $7 / 11$ & $39.1 \pm 16.3^{\dagger}$ & $9.9(1-30)$ & 28 \\
Unknown etiology & 50 & $5 / 6$ & $46.7 \pm 20.8^{\S}$ & $14.5(1-47)$ & 30 \\
Drug & 11 & $16 / 34$ & $63.1 \pm 14.9$ & $13.4(1-43)$ & 36 \\
\hline
\end{tabular}

n: number, M/F: males/females. HAV and HBV denotes hepatitis A virus and hepatitis B virus, respectively. ${ }^{*}$ Data are expressed as mean $\pm \mathrm{SD} .{ }^{\dagger} \mathrm{p}<0.001$ compared to the drug-induced group. ${ }^{8} \mathrm{p}<0.05$ compared to the drug-induced group. 
Table 3. Clinical Background of Patients with Fulminant Hepatitis According to the Year of Hospitalization

\begin{tabular}{lcc}
\hline & $1980-1989$ & $1990-1999$ \\
\hline $\mathrm{n}$ & 47 & 34 \\
$\mathrm{M} / \mathrm{F}$ & $17 / 30$ & $13 / 21$ \\
Age* & $47.0 \pm 19.6$ & $47.5 \pm 20.8$ \\
Pre-encephalopathy period (days) (range) & $21(1-47)$ & $14(1-43)$ \\
Survival rate (\%) & 30 & 36 \\
\hline
\end{tabular}

n: number, M/F: males/females. ${ }^{*}$ Data are expressed as mean \pm SD.

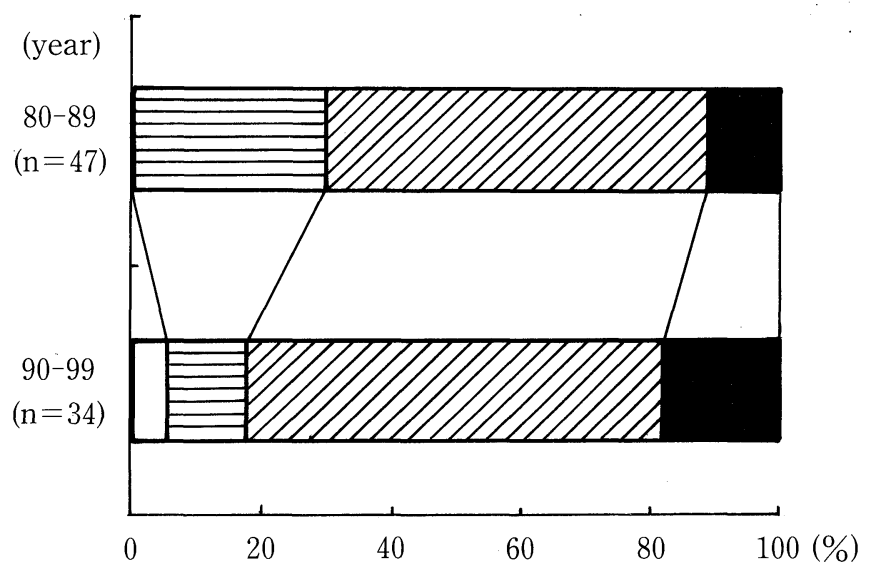

Figure 1. Changes in the etiology of fulminant hepatitis during the period of 1980 to 1999. $\square$ : hepatitis A virus, 冒: hepatitis B virus, $\mathbb{Z}$ : unknown etiology, $\square$ : drug-induced.

\section{Survival rate in patients with fulminant hepatitis}

Of 81 patients with fulminant hepatitis, $26(32 \%)$ survived. The survival rates in patients with fulminant hepatitis type $B$, fulminant hepatitis of unknown etiology and fulminant druginduced hepatitis were similar (Table 2). Though the fulminant hepatitis type A group consisted of only two cases, both survived. No gender difference was detected in the survival rate. In patients whose pre-encephalopathy period was $\leq 10$ days, survival rate in $\leq 39$-year-old patients was significantly higher than that in patients those $\geq 40$ years of age $(\mathrm{p}<0.05)$. This difference was not seen in patients whose pre-encephalopathy period was $\geq 11$ days (Table 4 ).

\section{Discussion}

In this study, $18(22 \%)$ patients had fulminant hepatitis type B. A previous Japanese report by Takahashi and Shimizu (11) showed that among 236 patients with fulminant hepatitis throughout Japan, $48 \%$ were diagnosed with fulminant hepatitis type B. The overall incidence of fulminant hepatitis type B in our study was slightly lower compared with the above-mentioned report. More importantly, however, the incidence of ful-
Table 4. Survival Rate in Patients with Fulminant Hepatitis According to the Duration of Pre-encephalopathy Period

\begin{tabular}{|c|c|c|c|c|}
\hline \multirow[b]{3}{*}{ Age (years) } & \multicolumn{4}{|c|}{ Pre-encephalopathy period } \\
\hline & \multicolumn{2}{|c|}{$\leq 10$ days } & \multicolumn{2}{|c|}{$\geq 11$ days } \\
\hline & $\mathrm{n}$ & Survival (\%) & $\mathrm{n}$ & Survival $(\%)$ \\
\hline$\leq 39$ & 20 & $12(60)^{*}$ & 8 & $2(25)$ \\
\hline$\geq 40$ & 24 & $4(17)$ & 29 & $8(28)$ \\
\hline
\end{tabular}

$* \mathrm{p}<0.05$.

minant hepatitis type B in our study decreased from $30 \%$ in $1980-1989$ to only $12 \%$ in $1990-1999$. The first half of this study (1980-1989) was almost the same period as that reported by Takahashi and Shimizu (11). A recent report from the Ministry of Health and Welfare in Japan also showed a higher incidence of fulminant hepatitis type B in 1989-1997 compared with our data, however, it had decreased during the observation period (13). The reduction in the number of patients with fulminant hepatitis type B seems to be associated with a reduction of the number of HBV carriers. Several investigators have recently reported patients with HBV-related liver diseases who were negative for serum HBV markers $(14,15)$. Using polymerase chain reaction (PCR), we have also shown the presence of HBV genome in the serum of more than half of the patients with fulminant hepatitis in Nagasaki Prefecture, though some of these patients were negative for HBsAg or IgM anti$\mathrm{HBc}(16)$. Interestingly, many patients with fulminant hepatitis type B showed a rapid clearance of HBsAg and early appearance of antibody to $\mathrm{HBsAg}$. This reason probably explains the frequent presentation of seronegative patients with fulminant hepatitis type $B$. Thus, it is likely that the number of patients with fulminant hepatitis type B would have been higher in the present study if PCR for HBV genome was performed. The number of patients with fulminant hepatitis type B as well as patients with all types of fulminant hepatitis has been diminishing in recent years. A high incidence of fulminant hepatitis type B has also been observed in Greece (17), India and France (18). In contrast, acetaminophen overdose is the leading cause of fulminant hepatitis in the United Kingdom (19) and United States (18).

In the present study, $50(62 \%)$ of 81 patients were found to have fulminant hepatitis of unknown etiology. The frequency of fulminant hepatitis of unknown etiology also decreased in the second half of our study. HAV and HBV are the major causative viruses of fulminant hepatitis in Japan. The importance of delta virus or hepatitis $E$ virus as a cause of fulminant hepatitis has also been demonstrated (1), however, the incidence of these forms of viral hepatitis in Japan is low $(20,21)$ and there are no reports of patients with fulminant hepatitis caused by these viruses in Japan. Furthermore, newly identified GBV-C/ HGV and TTV have not been reported to cause fulminant hepatitis $(5,6)$. Unfortunately, the relationship between fulminant 
hepatitis and GBV-C/HGV or TTV in this study was not clear because PCR for these viruses was not performed. Further efforts should be directed to find new viruses of fulminant hepatitis of unknown etiology.

The survival rates in patients with fulminant hepatitis type $\mathrm{B}$, fulminant hepatitis of unknown etiology and fulminant druginduced hepatitis were equal in our study (range, 28-36\%). Similar results were also reported by Takahashi and Shimizu (11). We also showed that the survival rate in the first half was equal to that in the latter half of the study. Liver transplantation is the most effective method for the treatment of fulminant hepatitis in other countries (22). It clearly improves the prognosis of patients with fulminant hepatitis (22). However in Japan, liver transplantation begun only recently and to date only a small number of patients have undergone such treatment. The present cases included only one patient treated by liver transplantation. In this study, the survival rate of patients younger than 39 years of age was significantly higher those over 40 years of age. This difference was only seen in patients whose pre-encephalopathy period was $\leq 10$ days. The reason for this difference is not clear at this stage as the etiologies and other factors in these groups were similar.

In conclusion, the incidence of fulminant hepatitis, especially that of fulminant hepatitis type B in Nagasaki Prefecture, has decreased in recent years. However, the survival rate has not improved in the past 20 years though various types of treatments have been tried.

\section{References}

1) Lee WM. Acute liver failure. N Engl J Med 329: 1862-1872, 1993 (published erratum appears in N Engl J Med 330: 584, 1994) (see comments).

2) Simons JN, Leary TP, Dawson GJ, et al. Isolation of novel virus-like sequences associated with human hepatitis. Nat Med 1: 564-569, 1995.

3) Linnen J, Wages J Jr, Zhang-Keck ZY, et al. Molecular cloning and disease association of hepatitis $\mathrm{G}$ virus: A transfusion-transmissible agent. Science 271: 505-508, 1996.

4) Nishizawa T, Okamoto H, Konishi K, Yoshizawa H, Miyakawa Y, Mayumi M. A novel DNA virus (TTV) associated with elevated transaminase levels in posttransfusion hepatitis of unknown etiology. Biochem Biophys Res Commun 241: 92-97, 1997.

5) Tanaka M, Nishiguchi S, Tanaka T, et al. Prevalence of GBV-C and hepatitis $\mathrm{G}$ virus variants in patients with fulminant hepatic failure in Japan. $\mathrm{J}$
Hepatol 27: 966-972, 1997.

6) Miyasaka A, Suzuki K, Abe K, et al. High prevalence of TT virus (TTV) in patients with nonA to nonG fulminant hepatitis: Differences of clinical features and prognosis between TTV positive and negative patients (in Japanese with English abstract). Nippon Rinsho 57: 1339-1344, 1999.

7) Matsuo A, Kusumoto Y, Ohtsuka E, et al. Changes in HBsAg carrier rate in Goto Islands, Nagasaki Prefecture, Japan. Lancet 335: 955-957, 1990.

8) Okuda K, Fujimoto I, Hanai A, Urano Y. Changing incidence of hepatocellular carcinoma in Japan. Cancer Res 47: 4967-4972, 1987.

9) Hamasaki K, Nakata K, Tsutsumi T, et al. Changes in the prevalence of hepatitis $\mathrm{B}$ and $\mathrm{C}$ infection in patients with hepatocellular carcinoma in the Nagasaki Prefecture, Japan. J Med Virol 40: 146-149, 1993.

10) Kato $Y$, Nakata $K$, Omagari $K$, et al. Risk of hepatocellular carcinoma in patients with cirrhosis in Japan. Cancer 74: 2234-2238, 1994.

11) Takahashi $Y$, Shimizu M. Aetiology and prognosis of fulminant viral hepatitis in Japan: A multicentre study. J Gastroenterol Hepatol 6: 159-164, 1991.

12) Trey C, Lipworth L, Chalmers TC, et al. Fulminant hepatic failure. Presumable contribution to halothane. N Engl J Med 279: 798-801, 1968.

13) Sato S, Suzuki K, Takikawa Y. Fulminant hepatitis. The Journal of the Japanese Society of Internal Medicine 88: 626-631, 1999 (in Japanese).

14) Zhang YY, Hansson BG, Kuo LS, Widell A, Nordenfelt E. Hepatitis B virus DNA in serum and liver is commonly found in Chinese patients with chronic liver disease despite the presence of antibodies to HBsAg. Hepatology 17: 538-544, 1993.

15) Kamito H, Nakata K, Hamasaki K, et al. Detection of hepatitis B virus genome in hepatocellular carcinoma from both hepatitis B surface antigen- and antibody to hepatitis $C$ virus-negative patients: A study using polymerase chain reaction. Oncol Rep 3: 619-623, 1996.

16) Inokuchi $K$, Nakata $K$, Hamasaki $K$, et al. Prevalence of hepatitis $B$ or $C$ virus infection in patients with fulminant viral hepatitis. An analysis using polymerase chain reaction. J Hepatol 24: 258-264, 1996.

17) Papaevangelou G, Tassopoulos N, Roumeliotou-Karayannis A, Richardson C. Etiology of fulminant viral hepatitis in Greece. Hepatology 4: 369372, 1984.

18) Lee WM, Schiфdt FV. Fulminant hepatitis. in Diseases of the Liver, : Schiff ER, Sorrell MF, Maddrey WC, Eds. 8th ed. Lippincott-Raven, Philadelphia, 1999: 879-895.

19) Mutimer DJ, Ayres RC, Neuberger JM, et al. Serious paracetamol poisoning and the results of liver transplantation. Gut 35: 809-814, 1994.

20) Mitamura K. Epidemiology of HDV infection in Japan. Prog Clin Biol Res 364: 81-87, 1991.

21) Dawson GJ, Chau KH, Cabal CM, Yarbough PO, Reyes GR, Mushahwar IK. Solid-phase enzyme-linked immunosorbent assay for hepatitis E virus IgG and IgM antibodies utilizing recombinant antigens and synthetic peptides. J Virol Methods 38: 175-186, 1992.

22) Rose HR, Martin P. Liver transplantation. in: Diseases of the Liver. Schiff ER, Sorrell MF, Maddrey WC, Eds. 8th ed. Lippincott-Raven, Philadelphia, 1999: 1589-1615. 